\title{
Longitudinal Patterns of Anxiety From Childhood to Adulthood: The Great Smoky Mountains Study
}

\author{
William E. Copeland, Ph.D., \\ Duke University Medical Center
}

Adrian Angold, M.R.C.Psych., Duke University Medical Center

Lilly Shanahan, Ph.D., and University of North Carolina at Chapel Hill

E. Jane Costello, Ph.D. Duke University Medical Center

\begin{abstract}
Objective-The aims of this study were twofold: 1) to provide a brief introduction to the prospective, longitudinal Great Smoky Mountains Study and review recent findings; and 2) to use this sample to conduct an epidemiologic analysis of common childhood anxiety disorders.

Method-The population-based Great Smoky Mountains Study assessed 1,420 participants from 11 counties in southeastern US up to 11 times between ages 9 and 26 with the structured Child and Adolescent Psychiatric Assessment and its upward extension, the Young Adult Psychiatric Assessment.

Results-The U-shaped age prevalence curve for any anxiety disorder was the product of high levels of childhood separation anxiety and adult panic, agoraphobia, and generalized anxiety. Over 1 in 5 subjects met criteria for an anxiety disorder by early adulthood. In terms of cumulative comorbidity, there was evidence of overlap between anxiety disorders, but the level of overlap was generally consistent with what is seen amongst other common childhood disorders. All childhood anxiety disorders were associated with adverse functioning in at least one young adult functional domain with the poorest outcomes for childhood generalized anxiety and DSM-III-R overanxious disorder.
\end{abstract}

Conclusion-Clinically significant anxiety is a common mental health problem to have had by adulthood. There was little evidence to support the consolidation of anxiety disorders, and some evidence to justify reintroduction of $D S M-I I I-R$ overanxious disorder. The transition to young adulthood appears to be a key period for understanding the development of common adult anxiety disorders such as panic and agoraphobia.

\section{Keywords}

anxiety; comorbidity; development; epidemiology; longitudinal

(C) 2013 American Academy of Child \& Adolescent Psychiatry. Published by Elsevier Inc. All rights reserved Correspondence to William E. Copeland, Ph.D., Center for Developmental Epidemiology, Duke University Medical Center, Department of Psychiatry and Behavioral Sciences, Box 3454, Durham NC 27710; William.Copeland@duke.edu.

Publisher's Disclaimer: This is a PDF file of an unedited manuscript that has been accepted for publication. As a service to our customers we are providing this early version of the manuscript. The manuscript will undergo copyediting, typesetting, and review of the resulting proof before it is published in its final citable form. Please note that during the production process errors may be discovered which could affect the content, and all legal disclaimers that apply to the journal pertain. 


\section{Introduction}

Over 50 years ago, Lapouse and Monk asserted that "One of the great psychiatric dilemmas of our time is the decision as to what is normal and what is abnormal in human behavior" (p. 1134). ${ }^{1}$ The controversy surrounding the recent publication of DSM 5.0 only confirms that this question continues to bedevil child psychiatry and motivate its investigators. Lapouse and Monk chose to address this dilemma by beginning one of the first epidemiological studies in child psychiatry on 482 children ages 6 to 12 in Buffalo, NY. There is now a long history of such studies in child psychiatry and they have gone far beyond the "mere counting of heads" (p. 646) ${ }^{2}$ to inform our etiological models of psychiatric disorders, to describe continuities and discontinuities across development, and to link mental health with other areas of functioning.

This paper will review one such study that was begun in the early 1990s to study the development of childhood psychopathology in 11 rural counties in western North Carolina ${ }^{3}$. To date, the Great Smoky Mountains Study has been following the original subjects for close to 20 years. The first part of this paper will provide a brief review of this study and draw attention to a number of recent findings - that can only be derived from a prospective, longitudinal study of this kind. The second part of the paper uses this distinctive study to conduct a developmental epidemiologic analysis of individual anxiety disorders from childhood to adulthood.

\section{The Great Smoky Mountains Study}

The Great Smoky Mountains Study (GSMS) was originally designed to examine the prevalence of common childhood psychiatric disorders, their development over time and use of mental health services in a predominantly rural area of the southeastern United States. At the time this study began there was no national survey to estimate the public health burden of childhood mental health problems or to identify the extent of met and unmet need. Furthermore, none of the ongoing epidemiologic studies had focused on rural areas where children are often isolated from access to specialty mental health services.

Given these aims, the study design had to balance identifying psychiatric cases with producing population prevalence estimates. A random household design might produce accurate prevalence estimates, but lack sufficient cases to develop risk models for individual psychiatric disorders. In contrast, a clinical sample would maximize case identification, but be of little use for epidemiologic prevalence and comorbidity estimates ${ }^{4}$. A screeningstratified sampling design achieves both aims by oversampling children scoring high on a screener, and then using sampling weights related to probability of selection to produce unbiased prevalence estimates ${ }^{5}$. Figure 1 shows how this design was implemented in the GSMS.

The GSMS area contains the Qualla Boundary, a federal reservation that is home to the Eastern Band of the Cherokee Indians, which has 8,000 enrolled members. While they make up only about $3 \%$ of the population of the study area, they were oversampled using the same screening procedure but recruiting everyone irrespective of their screen score. This provided a sufficient sample of American Indian children for computing epidemiologic estimates and testing risk pathways within this understudied group.

The original sample of 1,420 children included three cohorts ages 9,11, and 13 at baseline. Originally, assessment interviews were completed with the child and one parent (primarily mothers) each year as close to the child's birthday as possible (see Table 1). This strategy of annual assessments was continued through age 16 with a few exceptions due to financial 
restraints. Since age 16, the aim has been to interview all subjects at specific ages, a practice that is ongoing.

Originally, the primary assessment target was psychiatric function and service use, but the study also assessed related economic, psychosocial, and physical health constructs including family and community resources, family functioning, and exposure to adverse events, and physical health and development. Two finger-prick blood samples were collected with standardized collection paper at each in-person visit yielding 10 spots total. These dried bloodspots have since been assayed for sex steroid levels, hypothalamic-pituitary-adrenal (HPA) and immune function, and DNA methylation status. More recently, the focus of assessment has shifted to measuring long-term outcomes of psychiatric problems including physical health function, criminality, labor force outcomes, and adult social functioning. The competing aims of a prospective, longitudinal study are to collect similar measurements on similar constructs over time that allow one to assess developmental variation unaffected by measurement variance while simultaneously amending assessments to be up-to-date with scientific standards and relevant to the subject's current developmental stage.

Like many such long-term studies, the aims of GSMS have evolved. The sustaining value of such epidemiologic studies is derived from the methodological triangle of representative sampling, a prospective, longitudinal design, and cross-domain assessment. This value is maintained by minimizing attrition, continuous updating of the assessment battery, and selective adoption of novel methods. Below we provide three examples of recent GSMS findings that can only be derived from this type of prospective-longitudinal study, but were opportunities unforeseen at the study's inception.

\section{Depression and Puberty}

One of the most well-established findings in developmental psychopathology is the female predominance in unipolar depressions that appears around the age of $13^{6,7}$. This pattern implicates puberty, but puberty is a biologically driven developmental transition with complex secondary effects on social, emotional, and sexual development ${ }^{8}$. The longitudinal GSMS design allowed us to disentangle age from pubertal timing and pubertal stage. It was the transition to Tanner stage III of puberty that was associated with a sharp increase in rates of $D S M-I V$ unipolar depressions in girls, not the relative timing of this transition ${ }^{9}$. We next tested whether specific morphological changes or the hormonal changes underlying them accounted for the increased susceptibility to depression by assaying dried blood spots collected at each assessment for gonadal hormones and gonadotrophins (luteinizing hormone, follicular stimulating hormone, estradiol, testosterone). The Tanner stage effect was entirely explained by increasing levels of estradiol and testosterone ${ }^{10}$. Repeated measures of the same subjects, including sex steroids, proved necessary for testing competing pathways associated with the pubertal increase in female depression.

\section{Natural Experiment}

Children from impoverished families have higher levels of emotional and behavioral problems ${ }^{11,12}$. The challenge has been separating the effect of intergenerational social drift from social causation. The optimal study design would involve random assignment of families to different income strata ${ }^{13}$ but such experiments are rare. Four years into data collection for GSMS, a natural experiment was presented in which income levels in an entire community were raised - regardless of prior income status_-as a gambling casino was opened on the American Indian reservation. Every man, woman, and child within the tribe received a portion of the profits every 6 months (children's earnings were paid into a trust fund until adulthood). This income supplement (which reached an annual level of $\$ 6,000$ by 2001) raised many previously impoverished families above the federal poverty line. Moving 
out of poverty reduced children's rates of behavioral psychiatric symptoms to levels similar to those who were never poor ${ }^{14}$. These children continued to display lower rates of psychopathology, particularly substance disorders, into young adulthood ${ }^{15}$. This natural experiment provided support for the social causation theory that family poverty itself can be sufficient to increase risk for childhood behavior problems.

\section{Cumulative Prevalence}

Within any 3-month period during childhood, 13.3\% of GSMS subjects met criteria for a $D S M-I V$ disorder ${ }^{16}$. It is reasonable to suppose that the group of children meeting diagnostic criteria changes over time. This raises the question of how many children are affected by psychiatric disease at some point before adulthood. Lifetime prevalence estimates from a single retrospective interview suggest that about half of adults will meet criteria for a DSM$I V$ disorder by age $75^{17}$, but such a design is susceptible to bias. The repeated assessments from GSMS allowed us to estimate the cumulative prevalence of psychiatric problems with minimal risk of recall bias or forgetting. Despite the modest 3-month prevalence estimates, we found that $61.1 \%$ of the sample had met criteria for a DSM disorder by age 21 . An additional $21.4 \%$ of participants displayed subclinical psychiatric problems but never met full criteria for a DSM disorder. This brought the cumulative psychiatric burden to $82.5 \%$, despite only following subjects to age 21 and only assessing 3-month periods at each interview. Though commonly perceived as being uncommon or even rare, this study suggests most young adults have experienced mental illness at some period in development.

The three example findings described above underscore the value of epidemiologic studies followed prospectively across development and the importance of exploiting these uncommon resources. Accordingly, in the remainder of this paper, we leverage the 20-year longitudinal design of the GSMS to conduct an epidemiologic analysis of common anxiety disorders. Results from these analyses will inform our understanding of the developmental course and outcomes of individual anxiety disorders and their overlap.

\section{Anxiety Disorders}

A recent meta-analysis found that $12.3 \%$ of children have met criteria for an DSM-IV anxiety disorder at some point in middle childhood and $11.0 \%$ in adolescence ${ }^{18}$. It is estimated that between $15 \%$ and $30 \%$ of children and adolescents have been diagnosed with an anxiety disorder at some point in childhood ${ }^{19,20}$, with conflicting evidence about whether females are more susceptible than males (evidence for ${ }^{21,22}$; evidence against ${ }^{23}, 24$ ). Overall, anxiety disorders are common, and in females, they may be more common than any other disorder category 16,24 .

This conclusion, however, involves grouping together a host of disorders with distinct criteria and developmental features. Is this grouping justified? In his discussion of child psychiatric diagnosis and classification, Rutter suggested that in the case of anxiety disorders "there is something to be said in favor of eliminating all subcategories" (p. 649). ${ }^{25}$ $\mathrm{He}$ argued for such consolidation based on their high levels of co-occurrence and quantitative genetics findings. Grouping anxiety disorder has also been useful in determining the stability of anxiety and the association between childhood anxiety and longterm outcomes ${ }^{26}$, and in identifying underlying neural circuitry ${ }^{27}$. Furthermore, cognitive behavioral therapy and selective serotonin reuptake inhibitors are effective for a range of different anxiety disorders (e.g. ${ }^{28}$ ). Such consolidation would provide a simplified taxonomy that is both consistent with best practice treatment recommendations and a limited research base on differences between individual anxiety disorders. 
On a range of other metrics, however, there is evidence that individual anxiety disorders differ in important ways. Pine pointed out the unique course of many anxiety disorders in terms of developmental course, familial aggregation, comorbidity patterns, risk factors and biology while ceding the 'logic' of grouping such disorders for clinical purposes ${ }^{29}$. Furthermore, different childhood anxiety disorders predict different adult disorders $\left(\operatorname{se}^{19,30}\right)$. For example, the apparent association of childhood anxiety disorders with adult depression $16,21,31$ is accounted for by generalized anxiety only ${ }^{30}$. Similarly, different anxiety disorders may have differentiated predictions of other domains of later functioning. If individual anxiety disorders tell us something specific about one's long-term prognosis, then such distinctions may useful for clinicians and researchers alike.

This paper uses the GSMS to present a developmental epidemiologic analysis of childhood anxiety disorders. We will present the following: 1 ) developmental patterns of individual anxiety disorders; 2) cumulative prevalence estimates for individual disorders; 3 ) cumulative comorbidity rates between individual anxiety disorders; and 4) adult functional outcomes of individual childhood anxiety disorders. Together, these analyses provide a broad picture of the course and outcomes of individual disorders and their overlap that is lacking in the current literature.

Our previous work has implicated DSM-III-R overanxious disorder as a predictor of adult panic disorder over and above the contribution of other anxiety disorders ${ }^{30}$. Like GSMS, the New York Child Longitudinal Study found that overanxious disorder predicted adult psychiatric status and the authors suggested that this disorder should be retained in our diagnostic system ${ }^{21}$. These findings suggest that the $D S M-I V$ generalized anxiety may not be sufficient to assess the full range of "generalized anxiety" in children and adolescents. We believe that overanxious disorder continues to merit attention in our ongoing efforts to clarify the heterogeneity of childhood anxiety and thus we include it in all analyses below.

\section{Method}

The sampling, methods and sample characteristics were described above. Additional detail is available in prior publications ${ }^{3,16}$. Of the 1,420 subjects, $51.1 \%$ were female (unweighted $\mathrm{n}=630), 6.9 \%$ African American ( $\mathrm{n}=88)$ and 3.7\% American Indian $(\mathrm{n}=349) .34 .3 \%(\mathrm{n}=661)$ of subjects came from families that fell below the federal poverty line at least once during childhood.

\section{Procedure}

All interviewers were residents of the study area, had at least bachelor's level degrees, and received 1 month of training and ongoing quality control. Before the interviews began, parents and adult participants signed informed consent forms; informed assent forms were signed by minor children. Approval for this protocol was obtained from the Duke University Medical Center Institutional Review Board.

\section{Measures}

$D S M-I V$ psychiatric disorders were assessed using 1) the Child and Adolescent Psychiatric Assessment (CAPA ${ }^{24}$ until age 16, and 2) the upward extension of the CAPA, the Young Adult Psychiatric Assessment (YAPA) ${ }^{25}$ at ages 19, 21, and 24-26. Both a parent and the participating child were interviewed at ages 9-16; beginning at age 19 only the participant was interviewed. All interviews were coded by a trained interviewer and then checked by a supervisor. Anxiety disorders assessed included separation anxiety, generalized anxiety, social phobia, specific phobia, agoraphobia, and panic disorder, as well as DSM-III-R overanxious disorder. The time frame for determining the presence of psychiatric symptoms 
was the previous three months. Onset dates for all symptoms were also assessed, and were used in diagnostic algorithms when DSM-IV criteria required a symptom duration of 3+ months. A detailed glossary provides the operational rules for identifying clinically significant symptoms. Scoring programs for the CAPA and YAPA, written in SAS by the senior authors, combined information about the date of onset, duration, and intensity of each symptom to create diagnoses according to the DSM. A symptom was counted as present if reported by either parent or child or both, as is standard in child and adolescent epidemiological studies, approximating the process of combining information from multiple informants in clinical practice. Two-week test-retest reliability of CAPA diagnoses in children aged 10 through 18 is comparable to that of other structured child psychiatric interviews $^{23}, 32$. Construct validity as judged by 10 different criteria including comparison to other interviews and ability to predict mental health service use is good to excellent ${ }^{33}$. All measures, a glossary, and codebooks are provided at http://devepi.duhs.duke.edu/ instruments.html.

\section{Assessment of Adult Functioning}

Adult outcomes were assessed at ages 19, 21, and 24-26. All outcomes were assessed through self-report interviews with the Young Adult Psychiatric Assessment (YAPA) ${ }^{34,} 35$. The objective was to provide a broad profile of adult functioning across three domains: health, financial/educational, and social. Individual dichotomous indicators in each domain were aggregated into scales. These scales were standardized (mean: 0; SD: 1). Thus, "0" indicates the mean adult functioning in this sample). Additional information about individual indicators is available upon request from the first author.

Health Functioning-Participants reported being diagnosed with a serious/chronic illness or being in a serious accident at any point during young adulthood. Having a sexually transmitted disease was coded if the participant reported testing positive for herpes, genital warts, chlamydia, or HIV. Obesity was defined as BMI greater than $30 \mathrm{~kg} / \mathrm{m}^{2}$. Regular smoking was defined as smoking $>1$ cigarette per day for an extended period of time. A physical health problems survey adapted from CDC National Health Interview Survey (NIHS) Child Supplement (1988) was administered at all interviews. This assessed selfreported poor health, illness contagion, and slow illness recovery.

Financial/Educational Functioning-Being impoverished was coded based upon Census Bureau thresholds based on income and family size ${ }^{36}$. High school dropout and completion of any college completed were coded based upon the subject's educational status at the last adult assessment. The following job problems were assessed at each assessment: being dismissed or fired from a job and quitting a job without financial preparations. Finally, other financial problems were assessed using self-report: failing to honor debts or financial obligations and being a poor manager of one's finances (difficulty paying bills on time, no resources for emergencies, had car repossessed, or debt turned over to collector).

Social Functioning-Marital, parenthood, and divorce status were determined through self-reports at ages 24-26. The quality of the participant's relationship with their parents, spouse/significant other, and friends was assessed at each assessment including arguments and violence. Variables were included to indicate any self-reported violence in a primary relationship, a poor relationship with one's parents (based on either having no contact with parent or contact that is mostly conflictual and negative), no reported best friend or confidante, and difficulty making or keeping friends. 


\section{Missing Data}

Ninety-seven point five percent of participants provided more than one assessment, with over $79.4 \%$ of participants contributing at least 6 assessments (median $=7$; mode $=9$; range for completed assessments: 1 to 11). Thirty participants had died by age 26. Initial psychiatric state was unrelated to later missingness (OR=1.0, 95\%CI 0.9, 1.1, $p=.34)$, but individuals with more observations have more opportunities to meet criteria for a disorder. Therefore, cumulative prevalence and comorbidity analyses were completed on imputed datasets with SAS PROC MIANALYZE was used to read parameter estimates and associated covariance matrices for each imputed dataset and to derive valid statistical inferences and estimates ${ }^{37}$. Imputation details are available from the first author by request.

\section{Analytic Strategy}

As discussed above, sampling weights were applied to adjust for differential probability of selection and to insure that results represent unbiased estimates for the original population from which the sample was drawn. All reported prevalence rates are weighted. In addition, sandwich type variance corrections ${ }^{38}$ were applied to adjust for the parameter and variance effects induced by the sampling stratification. Weighted regression analyses were completed using PROC GENMOD in SAS 9.2 ${ }^{39}$.

\section{Results}

\section{Prevalence by Age}

Figure 2a shows the sex-specific 3-month prevalence rates from age 9 to 26 for having at least one anxiety disorder (i.e., social phobia, specific phobia, separation anxiety disorder, generalized anxiety disorder, panic disorder, and agoraphobia). The overall pattern is Ushaped with a sharp decrease in middle childhood followed by increasing levels from early adolescence to young adulthood. While the rates for females were slightly higher at various timepoints, this difference did not meet statistical significance overall, although there was evidence of a female preponderance in midadolescence and young adulthood $(p=0.032$ for age $15+)$.

Notably, the overall anxiety prevalence curve was not matched by any of the individual anxiety disorder prevalence curves. Thus, the overall anxiety disorder curve proved to be the average of several—quite different—age distributions of individual anxiety disorders that was not representative of any single disorder. Separation anxiety (Figure 2b) was common in middle childhood, but became vanishingly rare by early- to midadolescence. Social and specific phobia (Figures $2 \mathrm{c}$ and $2 \mathrm{~d}$, respectively) were both relatively uncommon (1\% or below) across development. In contrast, generalized anxiety disorder increased across adolescence with rates generally higher for females after mid-adolescence (Figure 2e; $p=0.035$ for age $15+$ ). Both agoraphobia and panic disorder (Figures $2 \mathrm{f}$ and $2 \mathrm{~g}$, respectively) were rare in childhood and adolescence then increased in young adulthood. For panic disorder, there was evidence that rates were higher in females in young adulthood, although even here the difference was not statistically significant ( $p=0.110$ for age 19+). DSM-III- $R$ overanxious disorder (Figure $2 \mathrm{~h}$ ) was more common in females across development, but did not vary by age.

\section{Concurrent Comorbidity Among Anxiety Disorders}

It is well established that anxiety disorders, like all common childhood disorders, frequently co-occur. 3.6\% ( $\mathrm{SE}=0.4$ ) of participants met criteria for an anxiety disorder at any given time, but only $0.5 \%$ of subjects or $13.8 \%$ of the those with an anxiety disorder met criteria 
for 2 or more anxiety disorders at any point in time. Thus, the majority of anxiety disorder cases were noncomorbid.

\section{Cumulative Prevalence}

Cumulative prevalence looks at the likelihood of having met criteria for a disorder at any observation by age 26 . Table 2 shows the cumulative 3 -month rates of anxiety disorder by age 26 . Over 1 in five subjects $(22.7 \%)$ had met criteria for an anxiety disorder by early adulthood. This estimate increased to 1 in 4 children when DSM-III-R overanxious disorder was included. The cumulative prevalence rate of any anxiety disorder was higher in females; this sex difference, however, was only statistically significant when overanxious disorder was included. The most common DSM-IV anxiety disorder was generalized anxiety followed by agoraphobia, separation anxiety, and panic disorder. DSM-III-R overanxious disorder was the most common disorder overall and the only disorder that was significantly more common in females than males.

\section{Cumulative Comorbidity}

Cumulative comorbidity shows how anxiety disorders overlap with one another over time as well as with other disorders. Table 3 displays the cumulative comorbidity rates from age 9 to age 26 . Of the 20 possible associations among anxiety disorders, 11 met standards for statistical significance and all odds ratios were greater than 1 . Generalized anxiety was most likely to be comorbid, overlapping with all other anxiety disorders except for agoraphobia. All other anxiety disorders overlapped with at least 2 other anxiety disorders with most odds ratios of association falling between 3 and 5. Higher levels of comorbidity were seen in social phobia with specific phobia where more than half of individuals with a specific phobia had met criteria for social phobia. DSM-III-R overanxious disorder also displayed high levels of overlap with generalized anxiety and panic disorder although in neither cases did more than half of the cases overlap.

Table 3 also displays the overlap between anxiety disorders and depression and behavioral disorders (conduct disorder, oppositional defiant disorder, attentiondeficit/ hyperactivity disorder [ADHD], and substance disorders). Generalized anxiety and panic disorder were associated with both categories; separation anxiety and social phobia were associated with depression only; agoraphobia and specific phobia (not shown) were not associated with either.

\section{Long-Term Outcomes}

Figure 3 displays the associations between childhood anxiety status (up to age 16) and three types of outcomes in young adulthood (ages 19, 21, and 24-26): health outcomes, financial outcomes, and interpersonal functioning. As compared to those with no childhood anxiety disorder, each individual childhood anxiety disorder was associated with adverse functioning in at least one young adult functional domain. Both generalized anxiety and overanxious disorder had poor functioning in all domains. Separation anxiety was associated with poor health outcomes and social phobia was associated with interpersonal problems.

\section{Discussion}

Since the advent of DSM-III in 1980, no new anxiety disorders have been added and 2 childhood disorders have been consolidated with adult counterparts (avoidant disorder with social phobia and overanxious disorder with generalized anxiety ${ }^{40}$. One question for future iterations of the DSM is whether further consolidation is warranted. Put differently, if the core feature of a set of disorders is shared, then what should be the standard for keeping these disorders separate? In the absence of an accepted standard, the current study uses a 
prospective, longitudinal study to look at similarities and differences across individual anxiety disorders.

The overall age prevalence curve of any anxiety disorder was not matched by the curve of even a single individual anxiety disorder. The age peaks in the overall rate of anxiety disorders were driven by different individual disorders with separation anxiety common early in development and generalized anxiety, panic, and agoraphobia common in young adulthood. The most prominent increases in anxiety disorders were associated with the transition to early adulthood, and the emerging anxiety landscape of young adulthood involves disorders without a specific, circumscribed fear (like specific phobia) and little evidence of attenuation with time. Unlike the pubertal transitions--which are distinctly biologically driven--the move from adolescence to young adulthood is characterized by distinct psychosocial events marking the transitions to adulthood, including independent living and fulltime employment. By their mid-20s, a quarter of subjects had met criteria for an anxiety disorder. This is not far from the projected lifetime prevalence of $31.5 \%$ given by the National Comorbidity Survey Replication ${ }^{17}$. The cumulative rates of generalized anxiety, panic and agoraphobia already met or exceeded the projected lifetime rates from studies based on retrospective recall by adults, casting further doubt upon accuracy of lifetime retrospective recall ${ }^{41,42}$. This is not to suggest that prospective, longitudinal studies are a panacea. Cumulative rates from such studies are always going to vary by the frequency of assessments, the period assessed, and the selection of informants. What is the true lifetime prevalence of anxiety disorders then? No single study can provide a satisfactory answer, but our findings suggest that anxiety is a common mental health issue to have had by adulthood and much more common than has previously been suggested.

At any given point in time it was uncommon for an individual with an anxiety disorder to have a comorbid anxiety disorder. This is not unexpected given the distinct age-prevalence pattern of individual disorders. Was the overlap between anxiety disorders over time higher than observed between other pairs of common disorders? There was evidence of overlap between anxiety disorders, as is the norm in child psychopathology ${ }^{43}$, but the levels of overlap were only slightly higher than is common between childhood disorders (ORs between 3 and 6 in Table 3). By way of comparison, the odds ratio of association between depressive disorders and behavioral disorders was 3.4 (95\% CI: 2.0-5.7). There was one exception: social phobia and specific phobia had a degree of overlap that might support the consolidation of these disorders. The other potential target for consolidation was of an anxiety with a nonanxiety disorder: generalized anxiety with depression. This is consistent with a host of prior studies ${ }^{4-46}$.

One of the ongoing questions regarding anxiety disorders is about their long-term prognosis. Separation anxiety disorder, for example, has a time-limited prevalence pattern-by adolescence it is nearly nonexistent. This contributes to the idea that some anxiety disorders may involve temporary distressing fears and worries but leave little lasting long-term effect. We have previously chronicled the links between childhood anxiety status and specific psychiatric outcomes into adulthood ${ }^{19,30}$. Here, we found that these long-term effects extend beyond psychiatric functioning: each childhood anxiety disorder was associated with poor functioning in an important adult functional domain.

Generalized anxiety was intended to replace $D S M-I I I-R$ overanxious disorder in identifying children with nonspecific, uncontrollable worry. Although these disorders were highly comorbid, most cases of either disorder were not comorbid with the other. The reintroduction of overanxious disorder to the DSM nosology has been proposed on the grounds that the overanxious criteria do not overlap with depression as is the case with generalized anxiety ${ }^{44}$. Our findings suggest that the overanxious criteria identified an 
independent group of children at risk for adult psychopathology and as well as other problems. As is, there is every reason for clinicians to continue (or to begin again) to assess the criterial symptoms of this disorder in their attempts to address current distress and to identify those patients at risk for long-term emotional problems.

The strengths of the sampling procedure, study design and assessment protocol have been discussed in detail, but the current sample is only representative of children from the area sampled, not all children in the US. Second, while the study is able to look at anxiety across middle childhood, adolescence, and early adulthood, it is clear that many children have already met criteria for an anxiety disorder by middle childhood ${ }^{47}$. Finally, the assessments sought to maximize accuracy of recall by focusing on a limited 3-month period, but this leaves 9 months unassessed between annual interviews. As such, our estimates are likely to represent the lower limit of the burden of anxiety disorders.

These findings provide little support for arguments to consolidate anxiety disorders, but they also have implications for our research agenda for anxiety disorders. Given the evidence of modest overlap between anxiety disorders, is there evidence of genetic, epigenetic, hormonal, or neural specificity for the individual disorders? Next, the period with the most dramatic changes in the rates of anxiety was the transition from adolescence to early adulthood. What aspects of this transition are associated with increased risk for agoraphobia, panic and generalized anxiety? Is this increased susceptibility simply a function of increased stress associated with the young adult transitions? Finally, all childhood anxiety disorders were associated with poor health functioning in young adulthood. Depression has been studied in relation to a range of physical health problems including heart disease and diabetes ${ }^{48,49}$. This finding suggests that similar attention should be paid to the physiological costs of anxiety.

\title{
Acknowledgments
}

The work presented here was supported by the National Institute of Mental Health (NIMH) (MH63970, MH63671, MH48085, MH094605), the National Institute on Drug Abuse (NIDA) (DA/MH11301), National Alliance for Research on Schizophrenia and Depression (NARSAD) (Early Career Award to W.E.C.), and the William T. Grant Foundation.

Dr. Copeland had full access to all the data in the study, performed all statistical analyses, and takes responsibility for the integrity of the data and the accuracy of the data analysis.

The authors would like to thank the participants of the Great Smoky Mountains Study and their families for their longstanding involvement in this study.

\begin{abstract}
This article is part of a special series on recent findings and progress in the fields of birth cohort and longitudinal studies of child and adolescent psychopathology. This special series is intended to showcase some of the most important new findings and promising leads in the study of developmental psychopathology over time and to demonstrate the Journal's renewed commitment to publishing the highest quality articles on the topic. Each article is in part a review of the most important findings to date from the study and in part original research to allow readers to learn about a new research finding with a more complete context of the study than is usually possible.

Disclosure: Dr. Copeland has received research support from the National Institute of Mental Health and NARSAD. Dr. Angold has received research support from NIMH, NIDA, and the National Institute of Child Health and Human Development. Dr. Shanahan has received research support from NIMH. Dr. Costello has received research support from NIMH and NIDA. Drs. Costello and Angold are corecipients of the 2009 National Alliance for Research on Schizophrenia and Depression Ruane Prize for Outstanding Child and Adolescent Psychiatric Research.
\end{abstract}

\section{References}

1. Lapouse RL, Monk MA. An epidemiologic study of behavior characteristics in children. American Journal of Public Health. 1958; 48(9):1134-1144. [PubMed: 13571479] 
2. Rutter M. Isle of Wight revisited. Journal of the American Academy of Child and Adolescent Psychiatry. 1989; 28:633-653. [PubMed: 2676960]

3. Costello EJ, Angold A, Burns B, et al. The Great Smoky Mountains Study of Youth: Goals, designs, methods, and the prevalence of DSM-III-R disorders. Archives of General Psychiatry. 1996; 53:1129-1136. [PubMed: 8956679]

4. Berkson J. Limitations of the application of fourfold table analysis to hospital data. Biometrics Bulletin. 1946; 2:47-52. [PubMed: 21001024]

5. Rothman, KJ.; Greenland, S. Modern Epidemiology. Second ed. Philadelphia: Lippincott-Raven; 1998.

6. Angold A. Childhood and adolescent depression I: Epidemiological and aetiological aspects. British Journal of Psychiatry. 1988; 152:601-617. [PubMed: 3048525]

7. Nolen-Hoeksema S, Girgus JS. The emergence of gender differences in depression during adolescence. Psychological Bulletin. 1994; 115(3):424-441. [PubMed: 8016286]

8. Hayward, C. Gender differences at puberty. New York: Cambridge University Press; 2003.

9. Angold A, Costello EJ, Worthman CM. Puberty and depression: The roles of age, pubertal status, and pubertal timing. Psychological Medicine. 1998; 28:51-61. [PubMed: 9483683]

10. Angold A, Costello EJ, Worthman CM. Pubertal changes in hormone levels and depression in girls. Psychological Medicine. 1999; 29(5):1043-1053. [PubMed: 10576297]

11. Bruce ML, Takeuchi DT, Leaf PJ. Poverty and psychiatric status: Longitudinal evidence from the New Haven Epidemiologic Catchment Area Study. Archives of General Psychiatry. 1991; 48:470474. [PubMed: 2021300]

12. Brooks-Gunn J, Duncan GJ. The effects of poverty on children. Future of Children. 1997; 7:55-71. [PubMed: 9299837]

13. Rutter M, Pickles A, Murray R, Eaves L. Testing hypotheses on specific environmental causal effects on bevavior. Psychological Bulletin. 2001; 127(3):291-324. [PubMed: 11393298]

14. Costello EJ, Compton SN, Keeler G, Angold A. Relationships between poverty and psychopathology: A natural experiment. JAMA. 2003; 290:2023-2029. [PubMed: 14559956]

15. Costello E, Erkanli A, Copeland W, Angold A. Association of family income supplements in adolescence with development of psychiatric and substance use disorders in adulthood among an american indian population. JAMA: The Journal of the American Medical Association. 2010; 303(19):1954-1960. [PubMed: 20483972]

16. Costello EJ, Mustillo S, Erkanli A, Keeler G, Angold A. Prevalence and development of psychiatric disorders in childhood and adolescence. Archives of General Psychiatry. 2003; 60:837-844. [PubMed: 12912767]

17. Kessler RC, Berglund P, Demler O, Jin R, Merikangas KR, Walters EE. Lifetime prevalence and age-of-onset distributions of DSM-IV disorders in the national comorbidity survey replication. Archives of General Psychiatry. 2005 Jun 1; 62(6):593-602. 2005. [PubMed: 15939837]

18. Costello EJ, Egger HL, Copeland W, et al. The developmental epidemiology of anxiety disorders: phenomenology, prevalence, and comorbidity. Anxiety disorders in children and adolescents: Research, assessment and intervention. 2011:56-75.

19. Bittner A, Egger HL, Costello EJ, Foley D, Angold A. What do childhood anxiety disorders predict? Journal of Child Psychology and Psychiatry. 2007; 48(12):1174-1183. [PubMed: 18093022]

20. Woodward LJ, Fergusson DM. Life course outcomes of young people with anxiety disorders in adolescence. Journal of the American Academy of Child and Adolescent Psychiatry. 2001; 40:1086-1093. [PubMed: 11556633]

21. Pine DS, Cohen P, Gurley D, Brook J, Ma Y. The risk for early-adulthood anxiety and depressive disorders in adolescents with anxiety and depressive disorders. Archives of General Psychiatry. 1998; 55:56-64. [PubMed: 9435761]

22. Wittchen H-U, Nelson CB, Lachner G. Prevalence of mental disorders and psychosocial impairments in adolescents and young adults. Psychological Medicine. 1998; 28:109-126. [PubMed: 9483687] 
23. Angold A, Erkanli A, Copeland W, Goodman R, Fisher PW, Costello EJ. Psychiatric Diagnostic Interviews for Children and Adolescents: A Comparative Study. Journal of the American Academy of Child \&amp; Adolescent Psychiatry. 2012; 51(5):506-517. [PubMed: 22525957]

24. Angold A, Erkanli A, Farmer E, et al. Psychiatric disorder, impairment, and service use in rural African American and White youth. Archives of General Psychiatry. 2002; 59:893-901. [PubMed: 12365876]

25. Rutter M. Research Review: Child psychiatric diagnosis and classification: concepts, findings, challenges and potential. Journal of Child Psychology and Psychiatry. 2011; 52(6):647-660. [PubMed: 21434914]

26. Caspi A, Henry B, McGee RO, Moffitt TE, et al. Temperamental origins of child and adolescent behavior problems: From age three to fifteen. Child Development. 1995; 66(1):55-68. [PubMed: 7497829]

27. Stein MB, Simmons AN, Feinstein JS, Paulus MP. Increased Amygdala and Insula Activation During Emotion Processing in Anxiety-Prone Subjects. Am J Psychiatry. 2007 Feb 1; 164(2):318327. 2007. [PubMed: 17267796]

28. Walkup JT, Albano AM, Piacentini J, et al. Cognitive Behavioral Therapy, Sertraline, or a Combination in Childhood Anxiety. New England Journal of Medicine. 2008; 359(26):27532766. [PubMed: 18974308]

29. Pine D. Commentary: Diagnosis and classification: There must be something left about which to argue - reflections on Rutter (2011). Journal of Child Psychology and Psychiatry. 2011; 52(6): 663-664. [PubMed: 21434916]

30. Copeland WE, Shanahan L, Costello EJ, Angold A. Childhood and Adolescent Psychiatric Disorders as Predictors of Young Adult Disorders. Arch Gen Psychiatry. 2009; 66(7):764-772. [PubMed: 19581568]

31. Kim-Cohen J, Caspi A, Moffitt T, Harrington H, Milne B, Poulton R. Prior juvenile diagnoses in adults with mental disorder: Developmental follow-back of a prospective-longitudinal cohort. Archives of General Psychiatry. 2003; 60:709-717. [PubMed: 12860775]

32. Angold A, Costello EJ. A test-retest reliability study of child-reported psychiatric symptoms and diagnoses using the Child and Adolescent Psychiatric Assessment (CAPAC). Psychological Medicine. 1995; 25:755-762. [PubMed: 7480452]

33. Angold A, Costello EJ. The Child and Adolescent Psychiatric Assessment (CAPA). Journal of the American Academy of Child and Adolescent Psychiatry. 2000; 39:39-48. [PubMed: 10638066]

34. Angold A, Costello E. The Child and Adolescent Psychiatric Assessment (CAPA). Journal of the American Academy of Child and Adolescent Psychiatry. 2000; 39:39-48. [PubMed: 10638066]

35. Angold, A.; Cox, A.; Prendergast, M., et al. The Young Adult Psychiatric Assessment (YAPA). Durham, NC: Duke University Medical Center; 1999.

36. Dalaker J, Naifah M. Poverty in the United States: 1997. U.S. Bureau of the Census, Current Population Reports: Consumer Income. 1998. 1993:60-201.

37. Rubin, DB. Multiple Imputation for Nonresponse in Surveys. New York, NY: John Wiley and Sons, Inc; 1987.

38. Pickles A, Dunn G, Vazquez-Barquero J. Screening for stratification in two-phase ('two-stage') epidemiological surveys. Statistical Methods in Medical Research. 1995; 4(1):73-89. [PubMed: 7613639]

39. SAS/STAT® Software: Version 9 [computer program]. Version. Cary, NC: SAS Institute, Inc; 2004.

40. American Psychiatric Association. Diagnostic and Statistical Manual of Mental Disorders Fourth Edition (DSM-IV). Washington, DC: American Psychiatric Press, Inc; 1994.

41. Moffitt TE, Caspi A, Taylor A, et al. How common are common mental disorders? Evidence that lifetime prevalence rates are doubled by prospective versus retrospective ascertainment. Psychological Medicine. 2009:1-11. First View. [PubMed: 19335938]

42. Copeland W, Shanahan L, Costello EJ, Angold A. Cumulative Prevalence of Psychiatric Disorders by Young Adulthood: A Prospective Cohort Analysis From the Great Smoky Mountains Study. Journal of the American Academy of Child \& Adolescent Psychiatry. 2011; 50(3):252-261. [PubMed: 21334565] 
43. Angold A, Costello EJ, Erkanli A. Comorbidity. Journal of Child Psychology and Psychiatry. 1999; 40:57-87. [PubMed: 10102726]

44. Lahey BB, Rathouz PJ, Hulle C, et al. Testing Structural Models of DSM-IV Symptoms of Common Forms of Child and Adolescent Psychopathology. Journal of Abnormal Child Psychology. 2008; 36(2):187-206. [PubMed: 17912624]

45. Moffitt TE, Harrington H, Caspi A, et al. Depression and Generalized Anxiety Disorder: Cumulative and Sequential Comorbidity in a Birth Cohort Followed Prospectively to Age 32 Years. Arch Gen Psychiatry. 2007 Jun 1; 64(6):651-660. 2007. [PubMed: 17548747]

46. Watson D. Rethinking the Mood and Anxiety Disorders: A Quantitative Hierarchical Model for DSM-V. Journal of Abnormal Psychology. 2005; 114(4):522-536. [PubMed: 16351375]

47. Egger HL, Angold A. Common emotional and behavioral disorders in preschool children: Presentation, nosology, and epidemiology. Journal of Child Psychiatry and Psychology. 2006; 47(3/4):313-337.

48. Wells KB, Rogers W, Burnam MA, Camp P. Course of depression in patients with hypertension, myocardial infarction, or insulin-dependent diabetes. American Journal of Psychiatry. 1993 Apr; 150(4):632-638. [PubMed: 8465882]

49. Copeland WE, Shanahan L, Worthman C, Angold A, Costello EJ. Cumulative Depression Episodes Predict Later C-Reactive Protein Levels: A Prospective Analysis. Biological Psychiatry. 2012; 71(1):15-21. [PubMed: 22047718] 


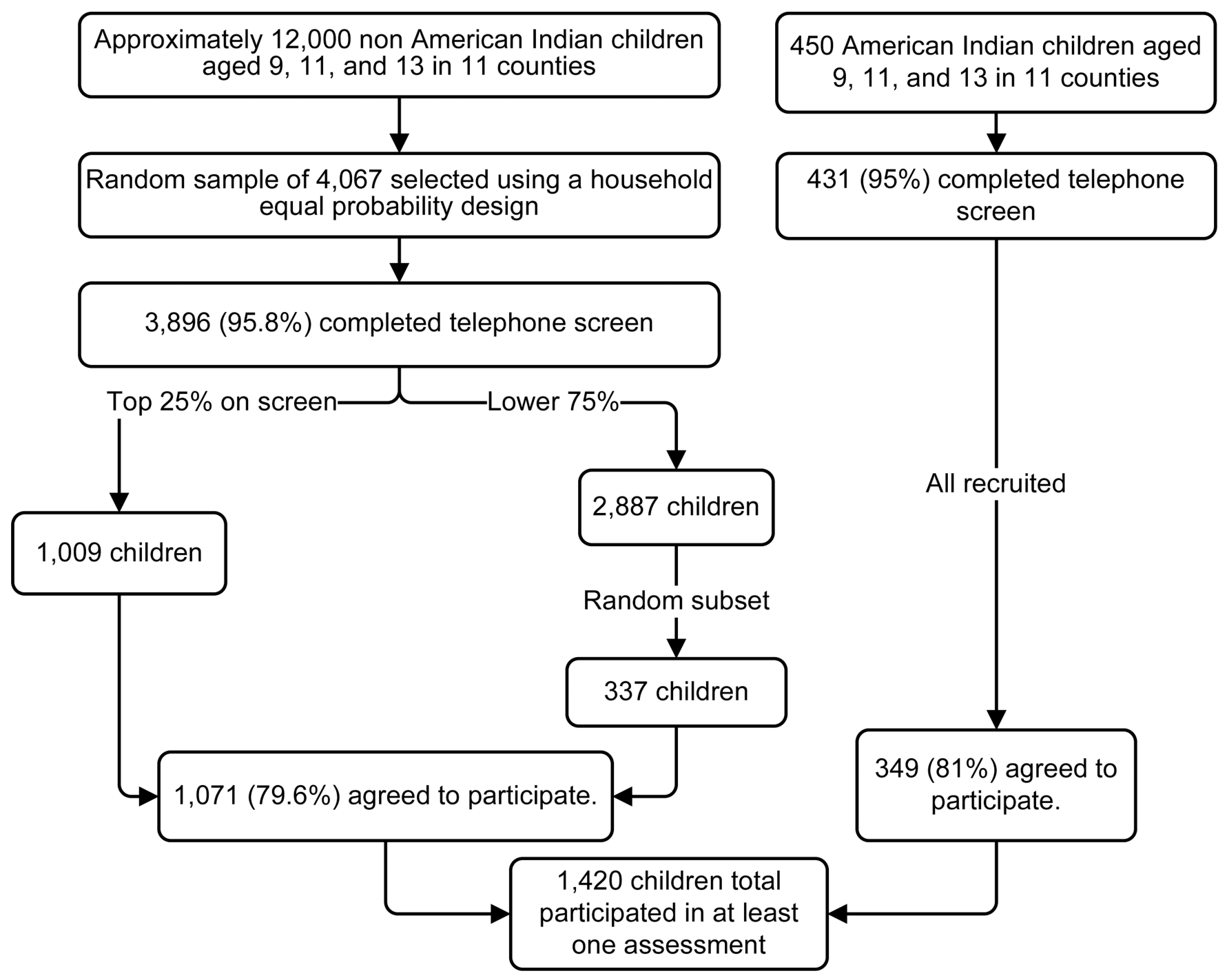

Figure 1.

Ascertainment figure for Great Smoky Mountains Study. 
A.

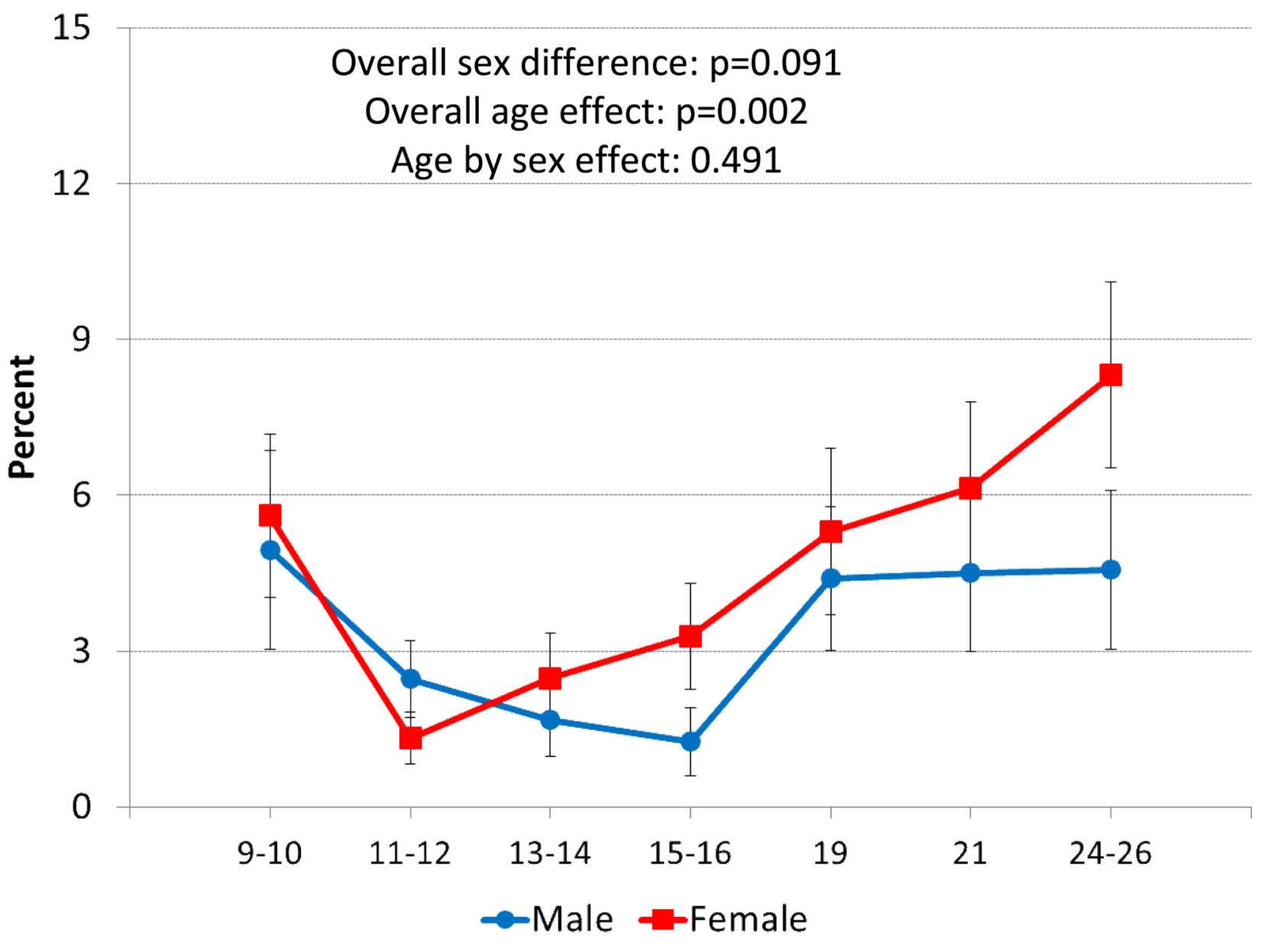


B.

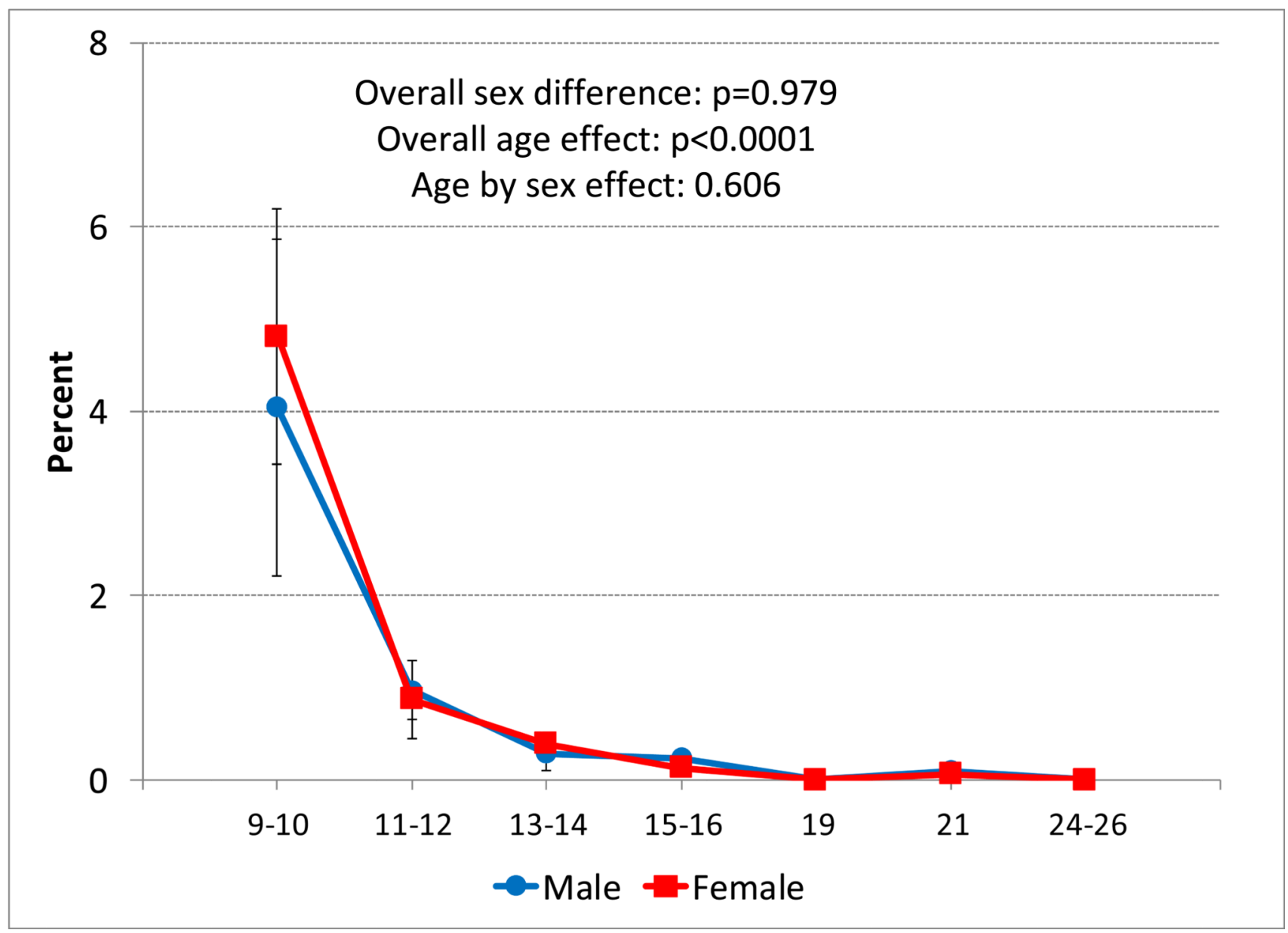


C.

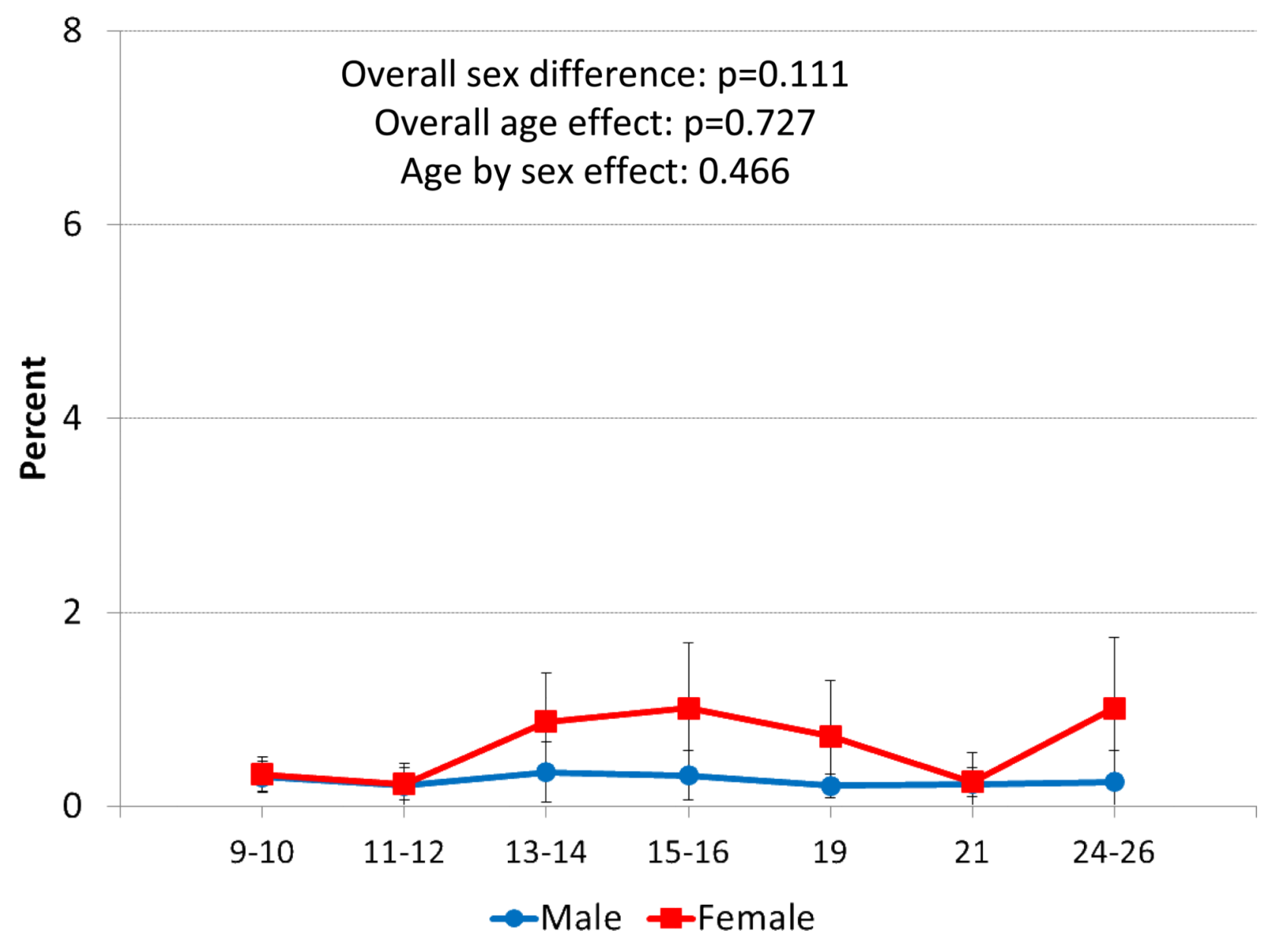


D.

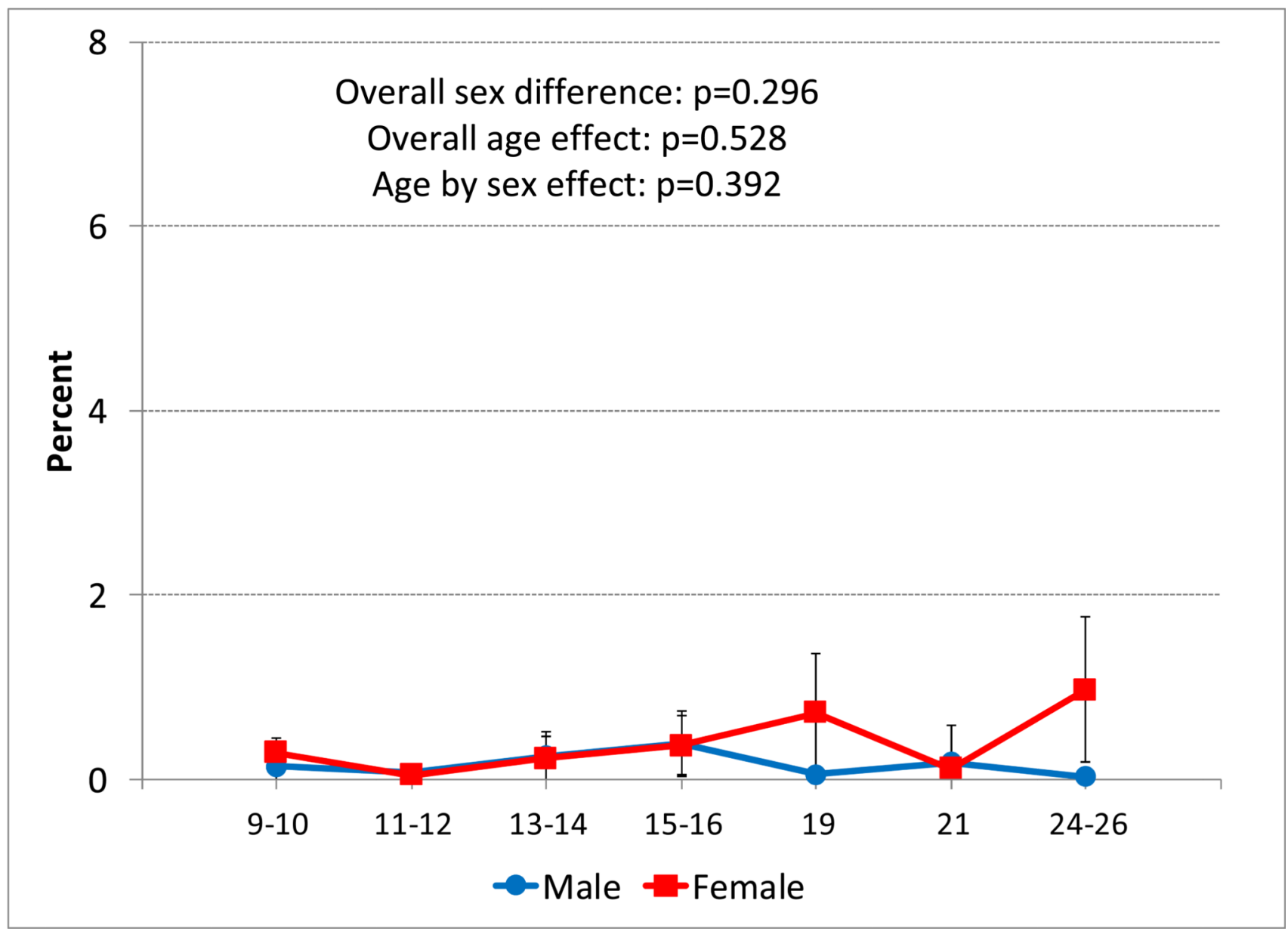


E.

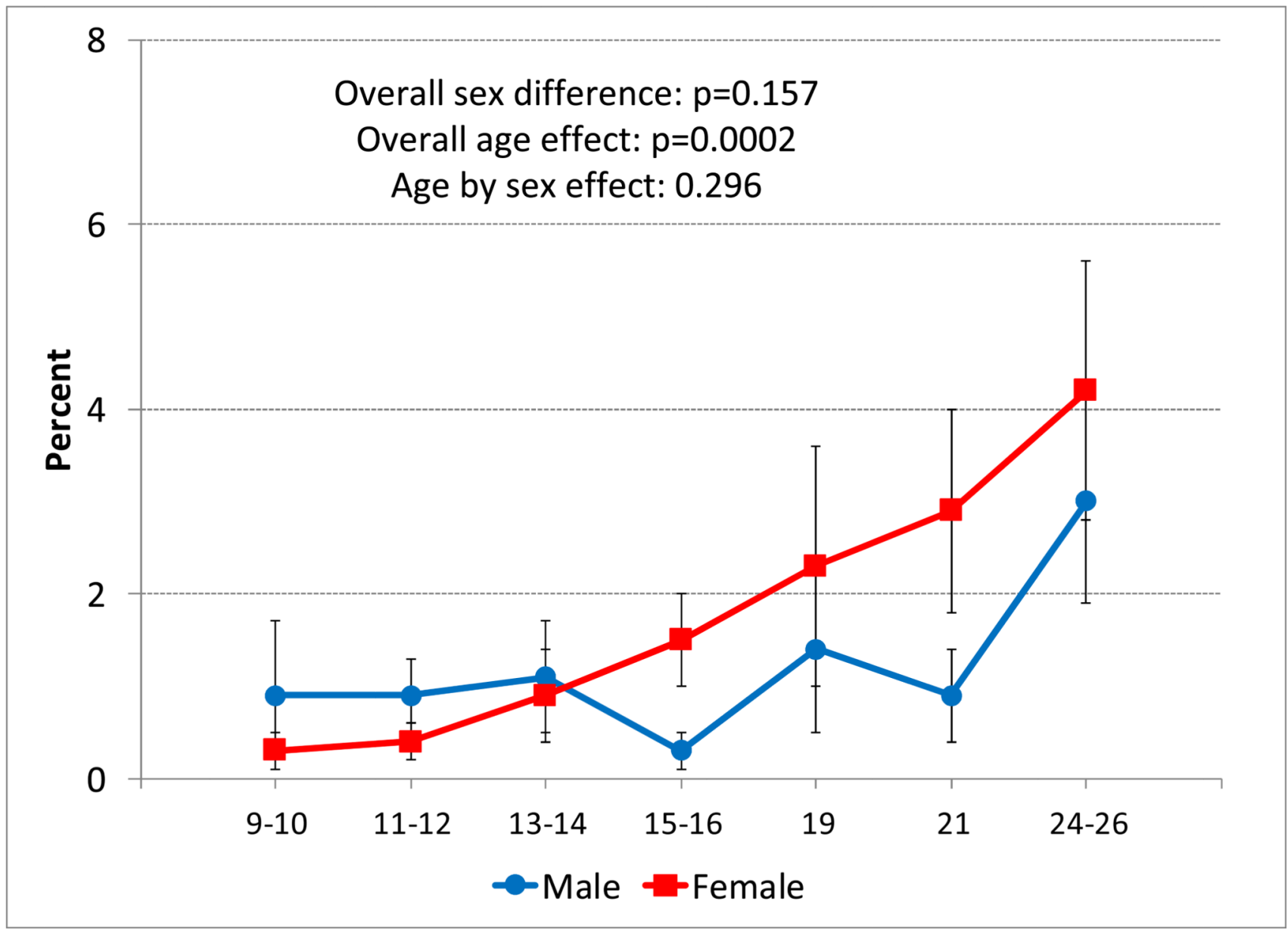


F.

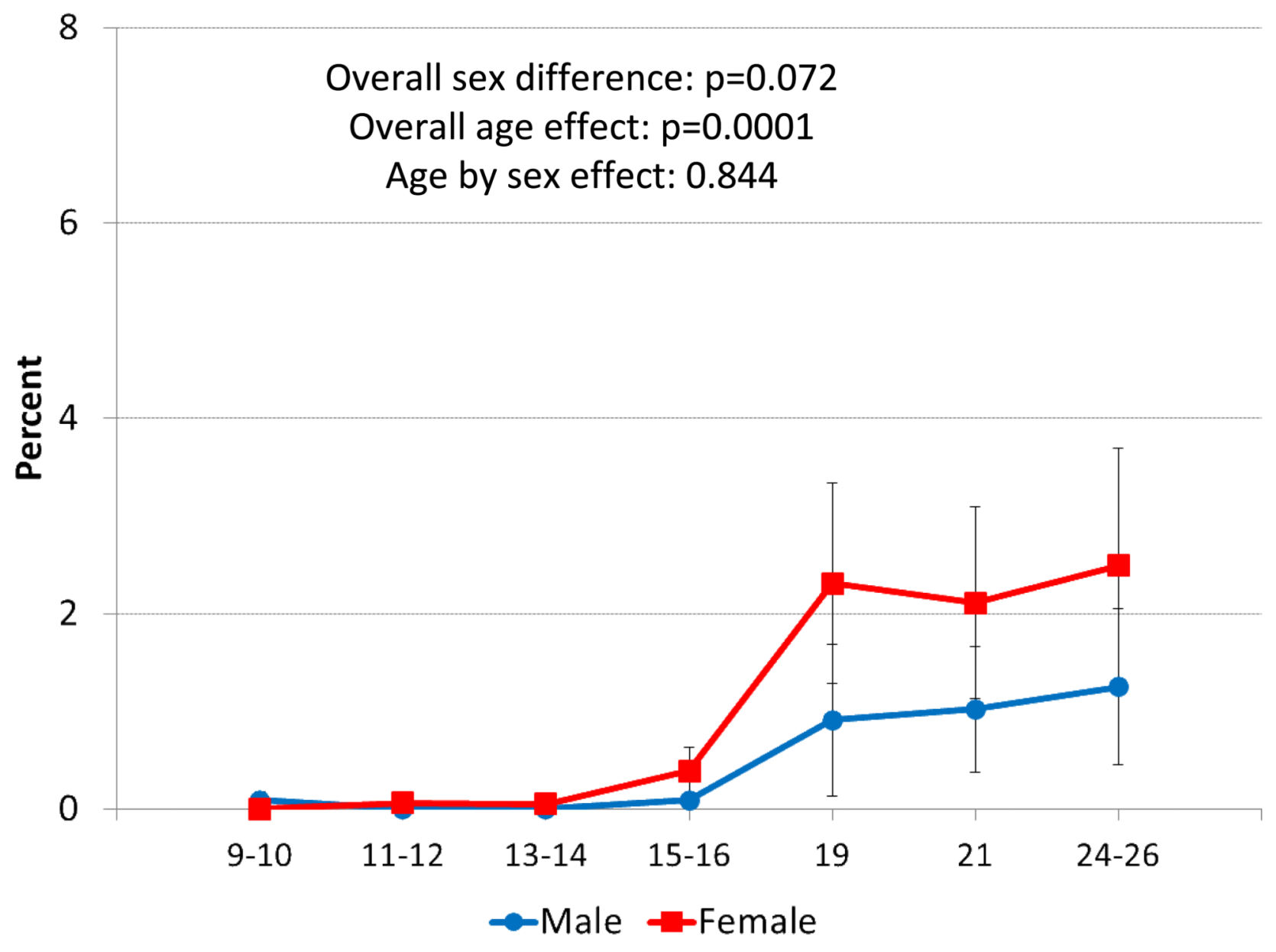


G.

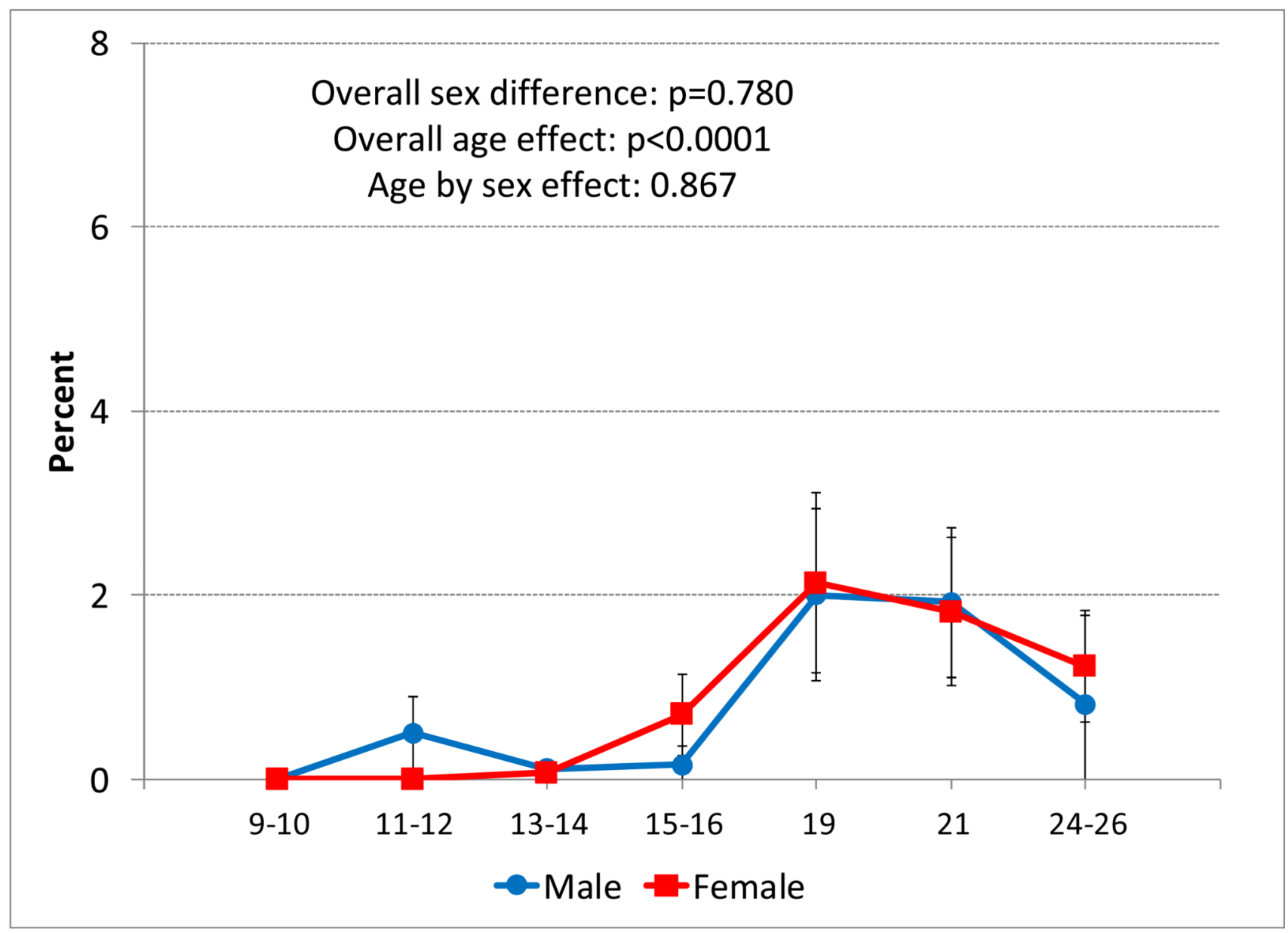


$\mathrm{H}$.

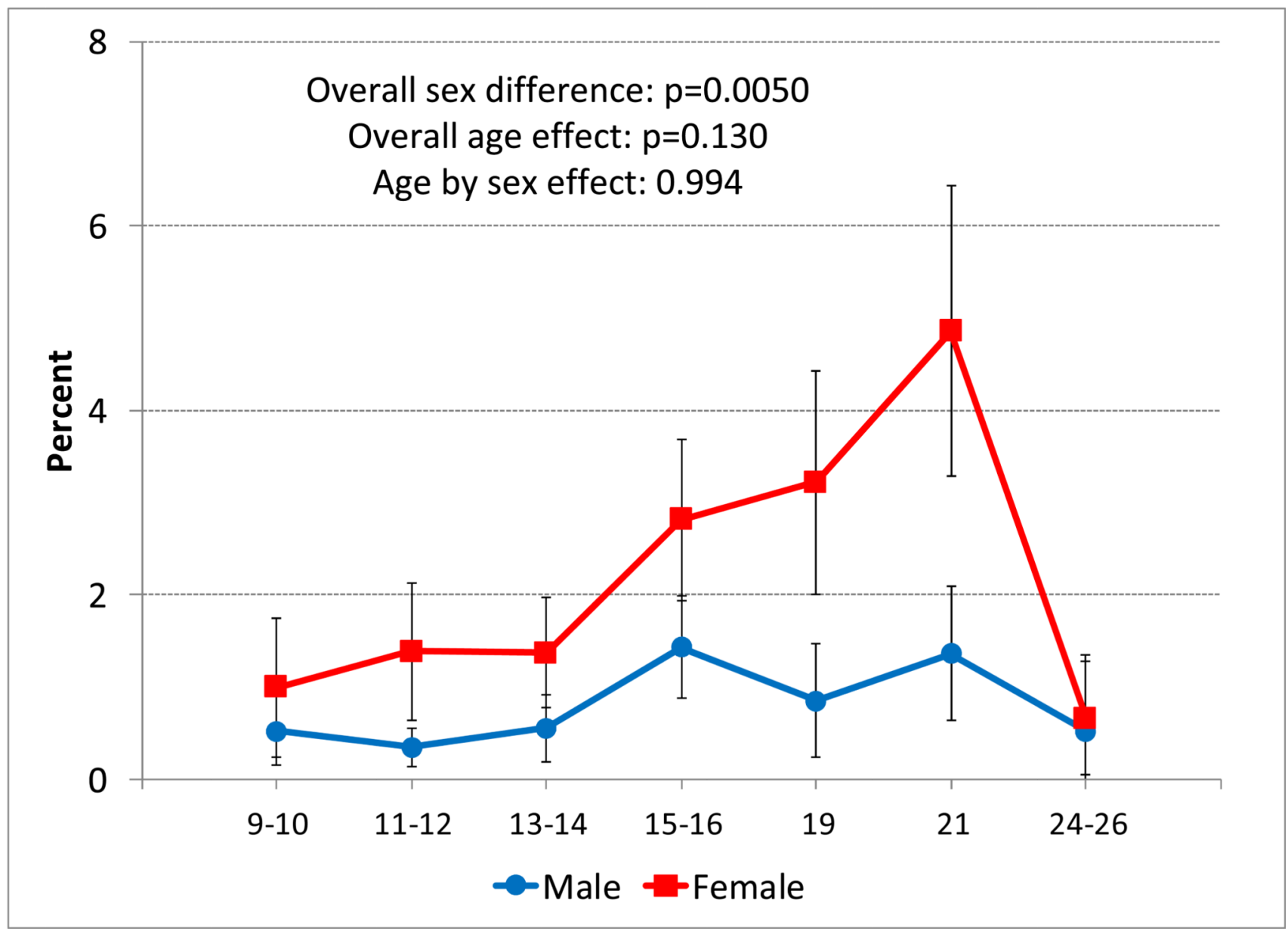

Figure 2.

Age-prevalence estimates for DSM anxiety disorders: A) Any $D S M-I V$ anxiety disorder; B) Separation anxiety; C) Social phobia; D) Specific phobia; E) Generalized anxiety; F) Panic disorder; G) Agoraphobia; H) DSM-III-R overanxious disorder. 


\section{None Separation Social $\square$ GAD Overanxious}

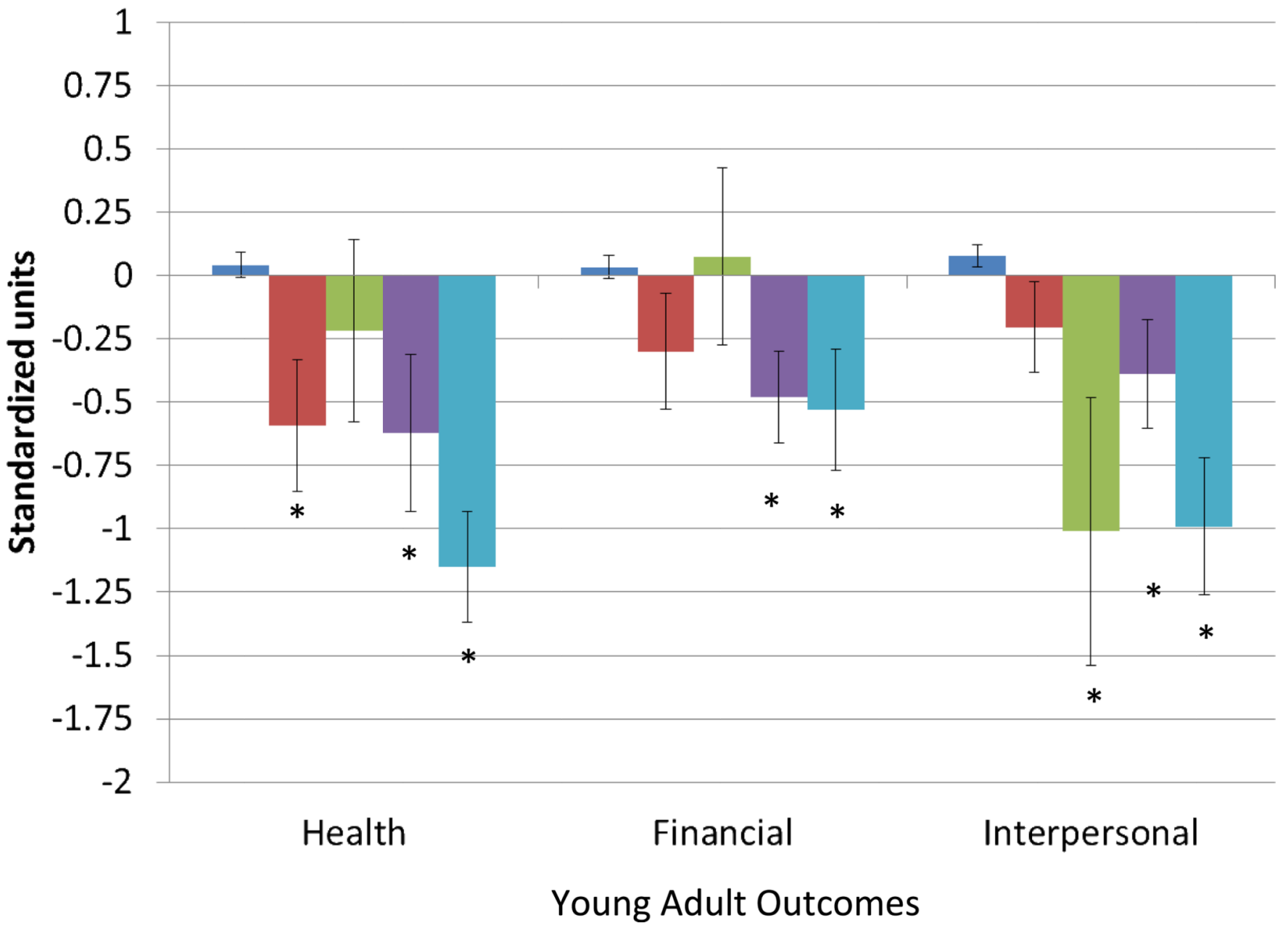

Figure 3.

Associations between childhood anxiety disorder status and outcomes in young adulthood.

Note: Starred bars are significantly different from the group with no childhood anxiety disorder. For health outcomes, subjects with a history of either separation anxiety (SEP) or generalized anxiety (GAD) had poor outcomes (SEP: $\beta=0.63$, SE=0.26, $p=0.015$; GAD: $\beta=0.66, \mathrm{SE}=0.17, p<0.001$ ), but not those with a history social phobia (SOC: $\beta=0.26$, $\mathrm{SE}=0.36, p=0.47$. Subjects with generalized anxiety had more financial problems in young adulthood (GAD: $\beta=0.51, \mathrm{SE}=0.19, p=0.006$ ). This was not the case for those with separation anxiety or social phobia (SEP: $\beta=0.33, \mathrm{SE}=0.23, p=0.15$; SOC: $\beta=-0.04$, $\mathrm{SE}=0.35, p=0.91$ ). Individuals with a history of either social phobia (SOC: $\beta=1.09, \mathrm{SE}=0.53$, $p=0.042$ ) or generalized anxiety (GAD: $\beta=-0.47, \mathrm{SE}=0.22, p=0.034$ ) had poor social outcomes. Those with a history of separation anxiety (SEP: $\beta=-0.28, \mathrm{SE}=0.18, p=0.13 \mathrm{did}$ not have significantly worse interpersonal outcomes than those with no history of childhood anxiety. Individuals with childhood overanxious disorder had poor health $(\beta=1.24, \mathrm{SE}=0.23$, $p<0.0001)$, financial $(\beta=0.58, \mathrm{SE}=0.24, p=0.017)$ and social outcomes $(\beta=1.10, \mathrm{SE}=0.27$, $p<0.0001)$. 


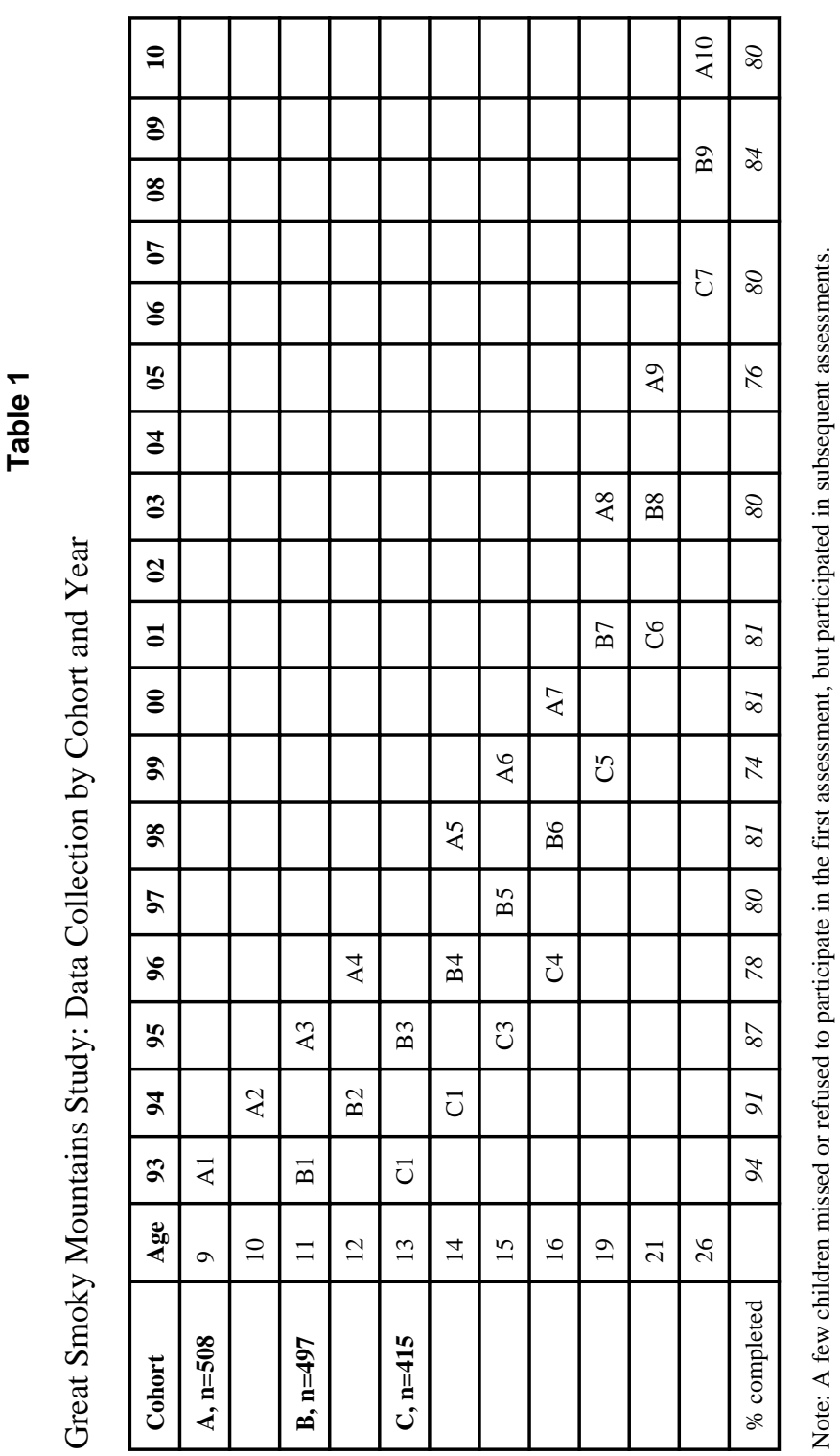

$J$ Am Acad Child Adolesc Psychiatry. Author manuscript; available in PMC 2015 January 01. 


\begin{tabular}{|c|c|c|c|c|c|c|c|c|c|c|c|}
\hline \multirow{3}{*}{ 告 } & 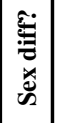 & $\approx$ & 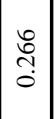 & $\mid$ & $\mid \begin{array}{l}0 \\
0 \\
\infty \\
0\end{array}$ & $\begin{array}{l}1 \\
\frac{1}{0} \\
0\end{array}$ & $\frac{\partial}{m}$ & 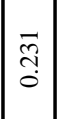 & 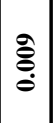 & $\frac{\vec{n}}{0}$ & $\mid \begin{array}{l}\infty \\
\vdots \\
0 \\
0\end{array}$ \\
\hline & 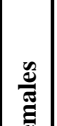 & $\begin{array}{l}\text { J } \\
8 \\
8 \\
\alpha\end{array}$ & \begin{tabular}{|l|}
$\vec{p}$ \\
$\vec{p}$ \\
$\infty$ \\
$\infty$ \\
$\stackrel{0}{-}$
\end{tabular} & $\left|\begin{array}{c}0 \\
\dot{d} \\
\tilde{1} \\
\tilde{d} \\
\tilde{d}\end{array}\right|$ & $\begin{array}{l}\stackrel{0}{0} \\
i \\
\infty \\
i \\
i\end{array} \mid$ & $\begin{array}{l}n \\
i \\
i \\
i\end{array} \mid$ & 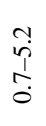 & \begin{tabular}{|l|}
0 \\
0 \\
$\dot{0}$ \\
+ \\
$\dot{b}$ \\
\end{tabular} & 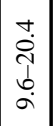 & $\begin{array}{l}m \\
a \\
i \\
i \\
m\end{array}$ & $\begin{array}{l}n \\
\hat{a} \\
\infty \\
i \\
i\end{array}$ \\
\hline & & $\therefore$ & \begin{tabular}{|l|}
\multirow{2}{*}{} \\
ஸे
\end{tabular} & $\begin{array}{l}\hat{\dot{e}} \\
\end{array}$ & in & \begin{tabular}{l|} 
\\
$\stackrel{\infty}{i}$ \\
$\dot{n}$
\end{tabular} & $\overrightarrow{\mathrm{i}}$ & $\stackrel{n}{=}$ & \begin{tabular}{l|}
0 \\
$\dot{n}$
\end{tabular} & 3 & ชู \\
\hline \multirow{5}{*}{ 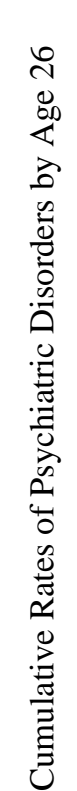 } & $\frac{\underline{y}}{\frac{y}{\pi}}$ & $\begin{array}{l}z \\
8 \\
8 \\
\alpha\end{array}$ & 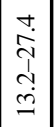 & 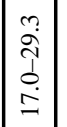 & $\begin{array}{l}m \\
i \\
i \\
\\
\end{array}$ & $\begin{array}{l}\infty \\
\stackrel{+}{ \pm} \\
\check{0} \\
0\end{array}$ & $\begin{array}{l}0 \\
\dot{j} \\
0 \\
\dot{0}\end{array}$ & \begin{tabular}{|l|}
0 \\
$\dot{7}$ \\
$\overline{1}$ \\
$\stackrel{+}{+}$ \\
$\dot{+}$
\end{tabular} & $\begin{array}{l}\partial \\
\hat{i} \\
\grave{i}\end{array}$ & $\begin{array}{l}a \\
\hat{j} \\
\hat{j} \\
0 \\
0\end{array}$ & $\mid$\begin{tabular}{c|}
2 \\
$\hat{1}$ \\
$\infty$ \\
$i$ \\
$c$
\end{tabular} \\
\hline & & $\therefore$ & 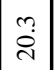 & \begin{tabular}{l|}
$\tilde{Z}$ \\
$\tilde{Z}$
\end{tabular} & $\left|\begin{array}{l}\infty \\
+\end{array}\right|$ & $\stackrel{n}{i}$ & $\stackrel{+}{-}$ & $\stackrel{0}{\infty}$ & $\begin{array}{l}3 \\
6\end{array}$ & $\stackrel{\vec{r}}{r}$ & 7 \\
\hline & 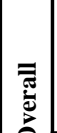 & $\begin{array}{c}z \\
\vdots \\
\vdots \\
\sigma\end{array}$ & 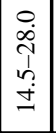 & $\mid$\begin{tabular}{c|}
$\vec{i}$ \\
$\vec{d}$ \\
0 \\
$\vec{i}$
\end{tabular} & 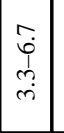 & $\mid \begin{array}{l}\vec{j} \\
\dot{j} \\
0 \\
\dot{i}\end{array}$ & $\mid \begin{array}{l}n \\
\tilde{\infty} \\
\infty \\
0 \\
0\end{array}$ & 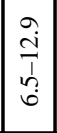 & 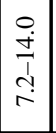 & \begin{tabular}{|l}
$\infty$ \\
0 \\
0 \\
0 \\
0 \\
$i$
\end{tabular} & $\mid \begin{array}{l}n \\
0 \\
o \\
i \\
c \\
n\end{array}$ \\
\hline & & $\therefore$ & $\hat{\mathrm{i}}$ & $\stackrel{\stackrel{i}{\sim}}{\mid}$ & in & $\stackrel{\sim}{\stackrel{f}{f}}$ & $\stackrel{i}{i}$ & $\grave{a}$ & $\stackrel{\circ}{\bigodot}$ & $\begin{array}{l}\infty \\
\dot{+} \\
\end{array}$ & $\overrightarrow{0}$ \\
\hline & & & 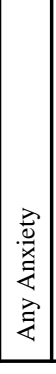 & 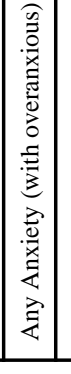 & 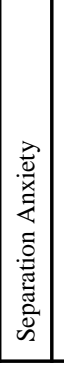 & 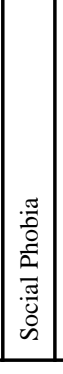 & 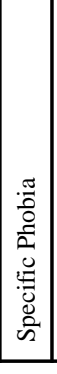 & 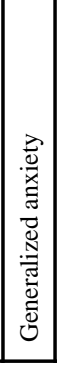 & 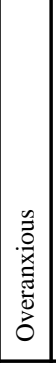 & 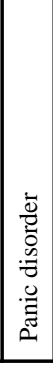 & 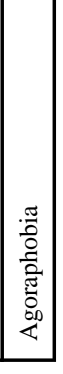 \\
\hline
\end{tabular}

J Am Acad Child Adolesc Psychiatry. Author manuscript; available in PMC 2015 January 01. 
政

0
0
0
0
0
0
0
0
0
0
0
0
0
0
0
0
0
0
0
0
0
0
0
0
0
0
0
0
0

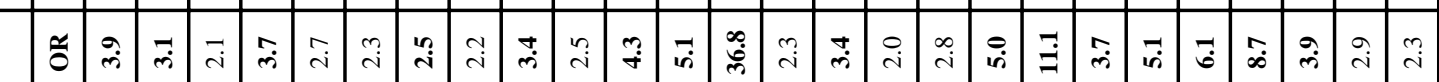

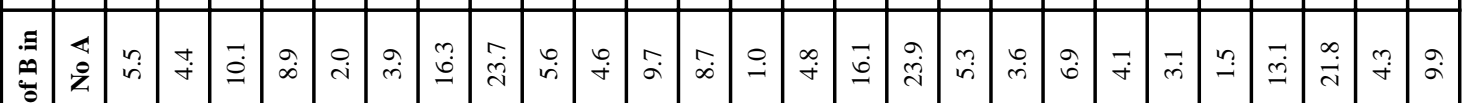

\begin{tabular}{|c|c|c|c|c|c|c|c|c|c|c|c|c|c|c|c|c|c|c|c|c|c|c|c|c|}
\hline$\sim$ & 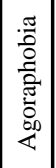 & 善 & 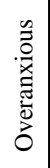 & 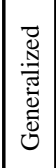 & $\mid$\begin{tabular}{|c|}
$\frac{\pi}{0}$ \\
$\frac{0}{2}$ \\
$\frac{2}{2}$
\end{tabular} & 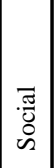 & 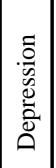 & 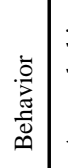 & 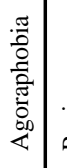 & 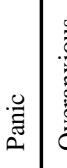 & & 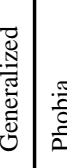 & 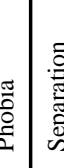 & 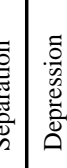 & 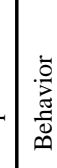 & 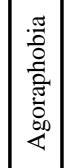 & . & 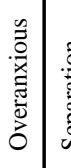 & 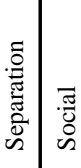 & 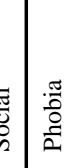 & 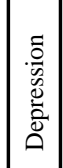 & 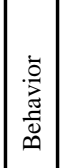 & 芯 & 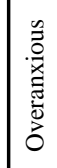 \\
\hline 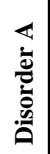 & 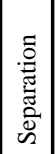 & 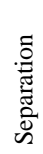 & 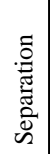 & 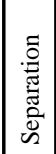 & 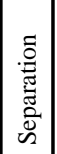 & 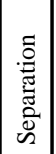 & 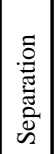 & 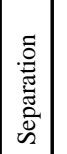 & 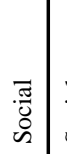 & 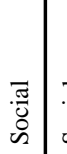 & $\begin{array}{cc}\overline{8} \\
\overline{0} \\
\bar{n}\end{array}$ & 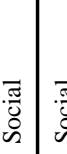 & 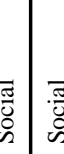 & 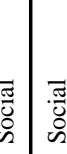 & 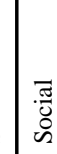 & 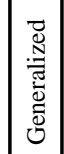 & 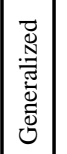 & 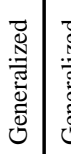 & 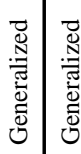 & 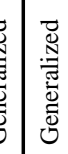 & 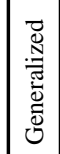 & 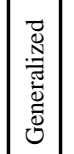 & 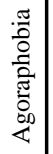 & 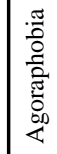 \\
\hline
\end{tabular}




\begin{tabular}{|c|c|c|c|c|c|c|c|c|c|c|c|c|c|c|c|}
\hline & 2 & $\begin{array}{l}0 \\
0 \\
0 \\
0\end{array}$ & 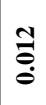 & 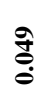 & ڤ్ & 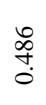 & $\begin{array}{l}\hat{a} \\
\hat{o}\end{array}$ & 志 & 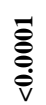 & $\bar{\Xi}$ & $\stackrel{\infty}{\stackrel{\infty}{0}}$ & ঙ্ণি & $\begin{array}{l}\text { tô. } \\
\stackrel{0}{0}\end{array}$ & 气̊: & $\stackrel{5}{0}$ \\
\hline & $\bar{\tau}$ & $\begin{array}{l}0 \\
\infty \\
0 \\
0 \\
0\end{array}$ & $\stackrel{\stackrel{J}{\Xi}}{\vec{J}}$ & 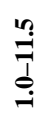 & $\begin{array}{l}= \\
+ \\
? \\
0\end{array}$ & $\begin{array}{l}r \\
\dot{n} \\
n \\
n \\
0\end{array}$ & 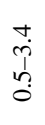 & $\begin{array}{l}0 \\
\stackrel{1}{1} \\
o \\
\text { a }\end{array}$ & 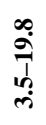 & 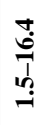 & $\begin{array}{l}\stackrel{+}{0} \\
\stackrel{i}{1} \\
\stackrel{0}{0}\end{array}$ & $\begin{array}{l}\stackrel{J}{*} \\
\stackrel{d}{b} \\
\stackrel{0}{0}\end{array}$ & 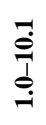 & 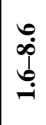 & $\begin{array}{l}\stackrel{3}{0} \\
\stackrel{1}{1} \\
\stackrel{-}{-}\end{array}$ \\
\hline & 믕 & $\stackrel{\infty}{i}$ & ले & $\stackrel{\vec{r}}{\dot{m}}$ & $=$ & $\stackrel{+}{\stackrel{H}{*}}$ & $\stackrel{m}{\longrightarrow}$ & $\vec{i}$ & $m_{\infty}^{\infty}$ & in & 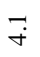 & $\stackrel{n}{i}$ & $\vec{r}$ & r & $\stackrel{n}{i}$ \\
\hline \multirow{2}{*}{ 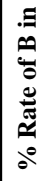 } & $\begin{array}{l}\mathbb{a} \\
\dot{z}\end{array}$ & $\stackrel{\infty}{\infty}$ & $\stackrel{m}{+}$ & $\hat{m}$ & $\tilde{\mathrm{i}}$ & $\underline{\sigma}$ & $\stackrel{\stackrel{\sim}{+}}{\sim}$ & $\hat{n}$ & $\stackrel{\hat{\infty}}{\infty}$ & $\begin{array}{l}0 \\
\infty\end{array}$ & $\stackrel{9}{-}$ & ले & 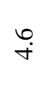 & $\begin{array}{l}\infty \\
\ddot{n}\end{array}$ & $\tilde{\sim}$ \\
\hline & $\varangle$ & $\begin{array}{l}0 \\
\stackrel{\vec{\lambda}}{ }\end{array}$ & 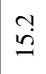 & $\overline{0}$ & $\stackrel{m}{i}$ & ì. & $\stackrel{\circ}{\circ}$ & $\stackrel{0}{\varrho}$ & $\stackrel{\text { f }}{\dot{f}}$ & $\stackrel{m}{\mathrm{I}}$ & $\underset{r}{\stackrel{\Delta}{r}}$ & ? & $\vec{g}$ & $\hat{q}$ & $\stackrel{\vec{f}}{\dot{\gamma}}$ \\
\hline \multirow{2}{*}{ 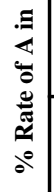 } & $\stackrel{\theta}{\ddot{z}}$ & in & $n$ & $\begin{array}{l}0 \\
\dot{n}\end{array}$ & $\overrightarrow{6}$ & ஸै & ชู & $\stackrel{?}{+}$ & $\stackrel{0}{\dot{m}}$ & $\stackrel{b}{\dot{m}}$ & $\stackrel{\bullet}{\dot{r}}$ & $\stackrel{b}{\dot{r}}$ & $\stackrel{\ominus}{+}$ & $\stackrel{\dot{c}}{\dot{r}}$ & $\stackrel{\infty}{\infty}$ \\
\hline & $\infty$ & $\stackrel{\sim}{m}$ & $\begin{array}{l}0 \\
\infty \\
\infty\end{array}$ & $\underline{\hat{\theta}}$ & $\underset{\sigma}{0}$ & $\begin{array}{l}n \\
\infty\end{array}$ & $\stackrel{\infty}{\sim}$ & 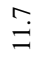 & ָ̊ & in & $\stackrel{n}{n}$ & $\hat{\varrho}$ & 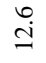 & $\overline{\mathrm{I}}$ & $\stackrel{\circ}{\circ}$ \\
\hline & 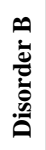 & 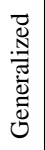 & 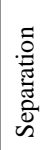 & 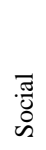 & $\begin{array}{l}\frac{\pi}{2} \\
\frac{0}{2} \\
\frac{1}{2}\end{array}$ & 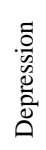 & 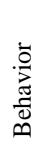 & 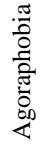 & 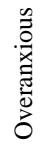 & 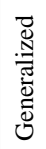 & $\begin{array}{l}\frac{\pi}{3} \\
\frac{2}{2} \\
\frac{2}{2}\end{array}$ & $\begin{array}{l}\overline{3} \\
\overline{8} \\
\text { n }\end{array}$ & 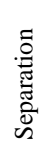 & 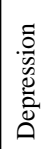 & 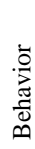 \\
\hline & 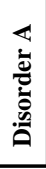 & 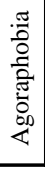 & 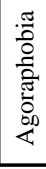 & 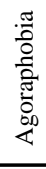 & 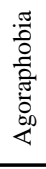 & 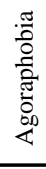 & 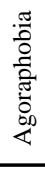 & 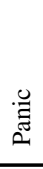 & $\begin{array}{l}\stackrel{0}{\Xi} \\
\tilde{\Xi}\end{array}$ & $\begin{array}{l}\text { 邑 } \\
\text { E }\end{array}$ & 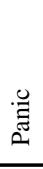 & 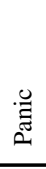 & 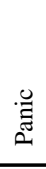 & 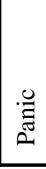 & 运 \\
\hline
\end{tabular}

